\title{
Pierre Gy (1924-2015): a monumental scientific life
}

\author{
Kim H. Esbensen
}

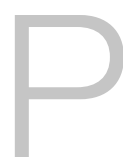

ierre Gy's legacy is both scientific and personal, for both community and individuals. My scientific tribute to Pierre can be found elsewhere in this issue.

I first met Pierre Gy in December 1998 when Professor Pentti Minkkinen called upon both of us as opponents at the defence for one of his PhD students, Riitta Heikka. I was the chemometric opponent while Pierre was the sampling expert par excellence. Aside from the serious academic duties discharged, this meeting allowed ample time for all three of us to get acquainted with one another for the first time. I had never met Pierre personally before. This meeting resulted in a $180^{\circ}$ change in my professional career.

A personal note: after many years of continually growing dissatisfaction with geochemical, technological and industrial sampling (today, we would call this "specimenting"), accumulated over the first two decades of my professional career in chemometrics, things really came to a head. Here at last was an explanation of the reason why so many chemometric models did not work in practice (a mystery to most chemometricians until the matter of proper data quality and proper validation was introduced in this field). The Theory of Sampling

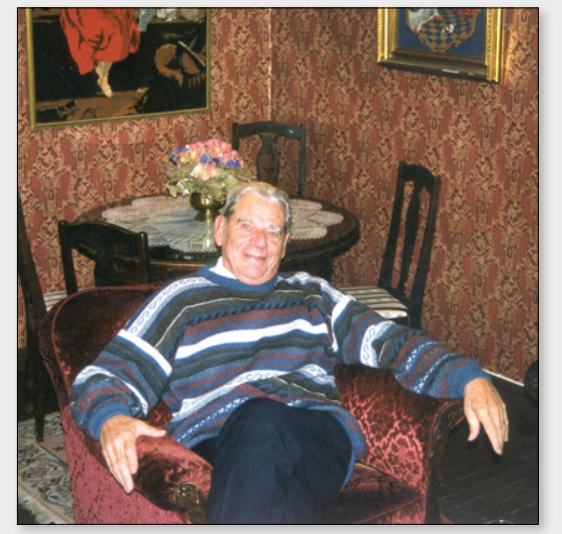

Pierre Gy at the Majorskaya Tea Salon, Lappeenranta, a Saturday in December 1998. My professional work was transformed forever.

(TOS) explained everything that was needed to understand these enigmas and also tells everything that is needed to do something effective to resolve issues... other than just talking about them. So after half a career exactly, I realised that it was time for a change: WHAT could be more important than inducting TOS into other fields of science tormented by unrecognised sampling error effects? ${ }^{1}$

My initial impression was that of Pierre's scientific overwhelming capacity and brilliance, which was accompanied by a rare
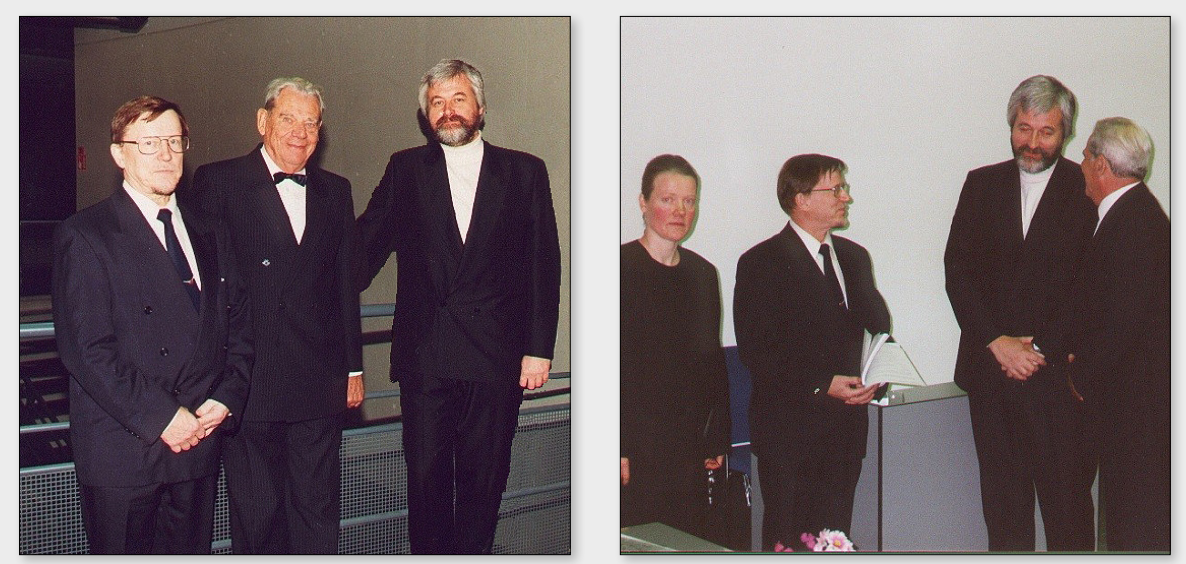

From a PhD defence in late 1998, Lappeenranta, Finland. The defence was a thoroughly happy affair. The three properly attired academic gentlemen met one-another for the first time. reciprocal characteristic: here was also a gentleman, with a very modest attitude and demeanour (exceedingly rare traits in the overly brash, competitive academic world).

After this meeting I immediately started invoking TOS in my academic work at two universities (HIT, Norway and AAU, Denmark), deliberately focusing on didactic ways and means to broaden the potential impact of TOS, along with chemometrics and process analytical technology (PAT). In this context I was highly appreciative that Pierre found occasion to participate in two, very different conferences soon after: the first took place in 1999 in Porsgrunn, Norway, the second in 2003 was the inaugural WCSB1 in Esbjerg, Denmark.

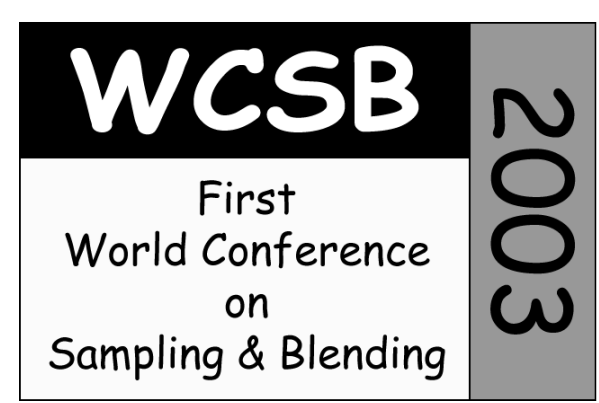

In "A Personal History" paper in the WCSB1 Proceedings (reprinted in this issue), Pierre details what these events meant to him. Additional historical facts, surrounding these two events follow below.

\section{Norwegian sojourn: scientific and personal}

In 1999 I had the honour of organising the $6^{\text {th }}$ Scandinavian Symposium on Chemometrics (SSC6), in Porsgrunn, Norway. ${ }^{2}$ Sampling and TOS were introduced to this field with prominence on this occasion, since Pierre had accepted my invitation as keynote lecturer. Finally, a head-on introduction of exactly what had been missing in chemometrics in its entire 40+ year history up to then! I was optimistic that most of the conference attendees would be ready to listen to the important and valuable messages offered by TOS, and would begin to consider how it could broaden the scope of data analysis in general, and of chemometrics in particular. Who better to hear it 
from then the originator himself? I placed the keynote lecture between the main course and the desert at the gala dinner as a reflection of the grandeur of the moment! Alas, I have an admission to make herethis placement was perhaps the most blatant misjudgement in my entire academic career! Disaster followed.

As the lecture progressed a great commotion (complete with increasing noise level) could be felt (and heard) from the conference bar, which was situated just outside the open door of the dining area. Typically, such an intense chatter is considered a hallmark of a successful scientific conference-only not at this specific time-andplace on the programme when the lecture was only about halfway through. As matters progressed and the volume increased, I became more and more worried... more and more than a few of the delegates did not grasp the historic moment and the transformational message... quite au contraire! In the end I was completely mortified on behalf on the chemometric societysuch disregard!

However, Pierre Gy revealed his true gentleman's attitude when trying to console me (not the other way around): "These are young kids-do not worry about them. They will either see the light later in their careers, or they will not. It is only important to try to turn things around, and do betterit does not matter in the eyes of history how long our endeavours take". Here I learned an essential lesson in patience and humility, and since the conference was otherwise a resounding success, we decided to move on from this historical intermezzo. Truth be told, this fiasco has been a source of much amusement ever since.

Indeed the conference also had another meaning for Pierre and his wife Sylvia, a matter of quite a different kind. Before the conference Pierre had asked me a personal favour: "Please help me locate a region, in
Norway bearing the prefix "Gy..." or any derivative thereof.... It is essential that any area so identified was a region of Norway that was home to Vikings approximately 1000 years ago". Despite my initial thought, which was to be somewhat mystified, this turned out to be an easy quest.

The photograph below, taken by Pierre himself in 1999, stems from the post-conference tour of Norway he and Sylvia enjoyed. Later he told that he had indeed found "his Gyland", the very region in southern Norway from where his family's ancestors in the Normandie originated-"just 1000 years ago". The Gy family annals are quite certain and specific regarding its Viking roots. This trip provided him a chance to close a 1000year historic circle. He told me later how he revelled in telling his family all the details from this rare opportunity to enrich the historical family background and perspective.

Not long after this conference Pierre again visited Norway, this time for a full-length course on TOS, with a decidedly more attuned audience from both academe and industry. From this event there are only fond memories-let history show some moments thoroughly enjoyed by Pierre of both the impact of the lectures (right, opposite) as well as the extraordinary camaraderie experienced (left, opposite).

\section{A return to roots and a new beginning}

I changed academic affiliation in the summer of 2001 when I began a 10-year affiliation with Aalborg University, campus Esbjerg, in my native country of Denmark. My first job was to place TOS on the academic curriculum that I was responsible for. As part of that I was surprised and intrigued by the fact that there had never been any meeting or conference dedicated to the science of sampling, none, never! I decided to take a giant leap and organise the first world conference dedicated to sampling,

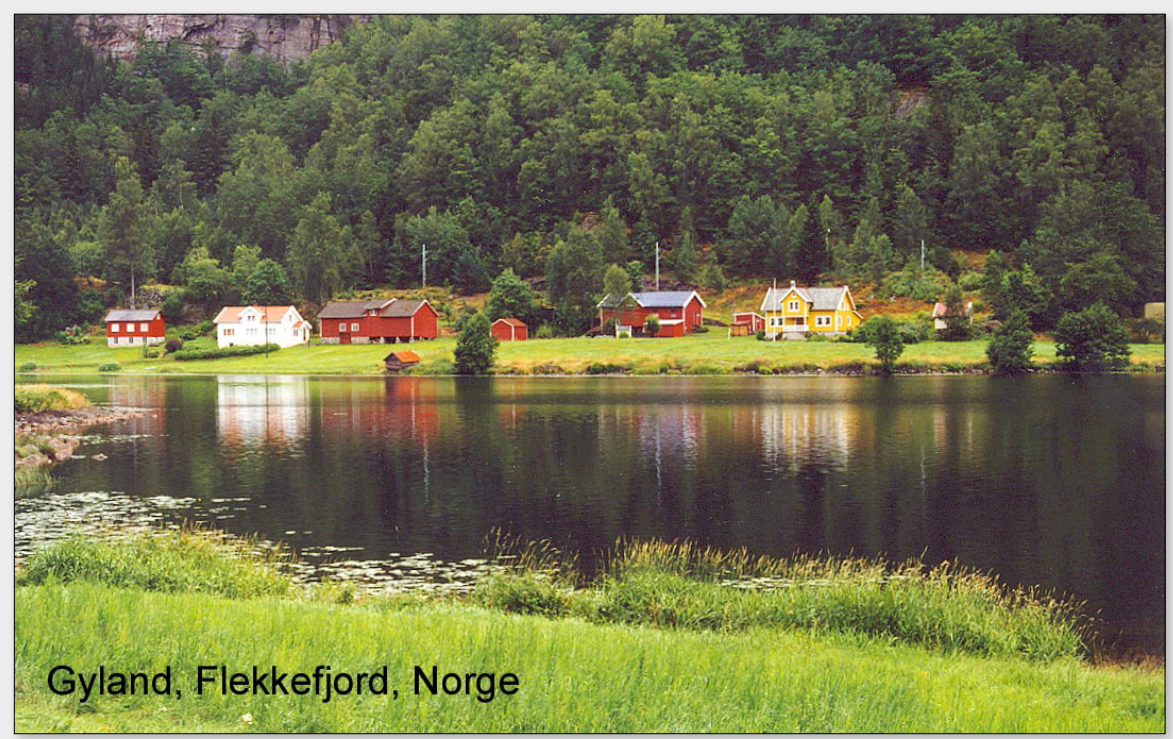

This geographical family heritage was so important for Pierre that he included this photo, as well as several others from this post-conference Norwegian sojourn, in his later TOS lectures.

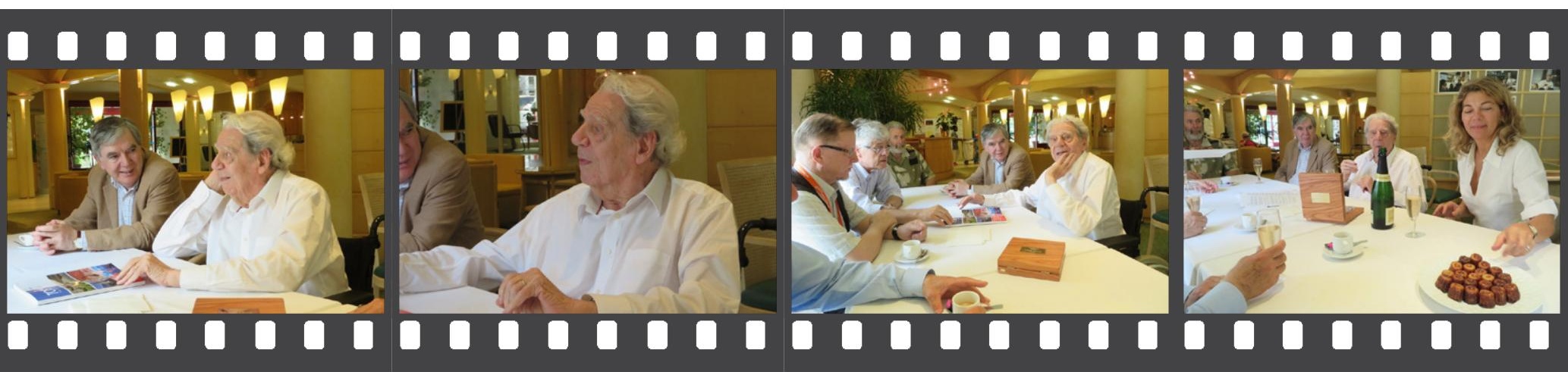




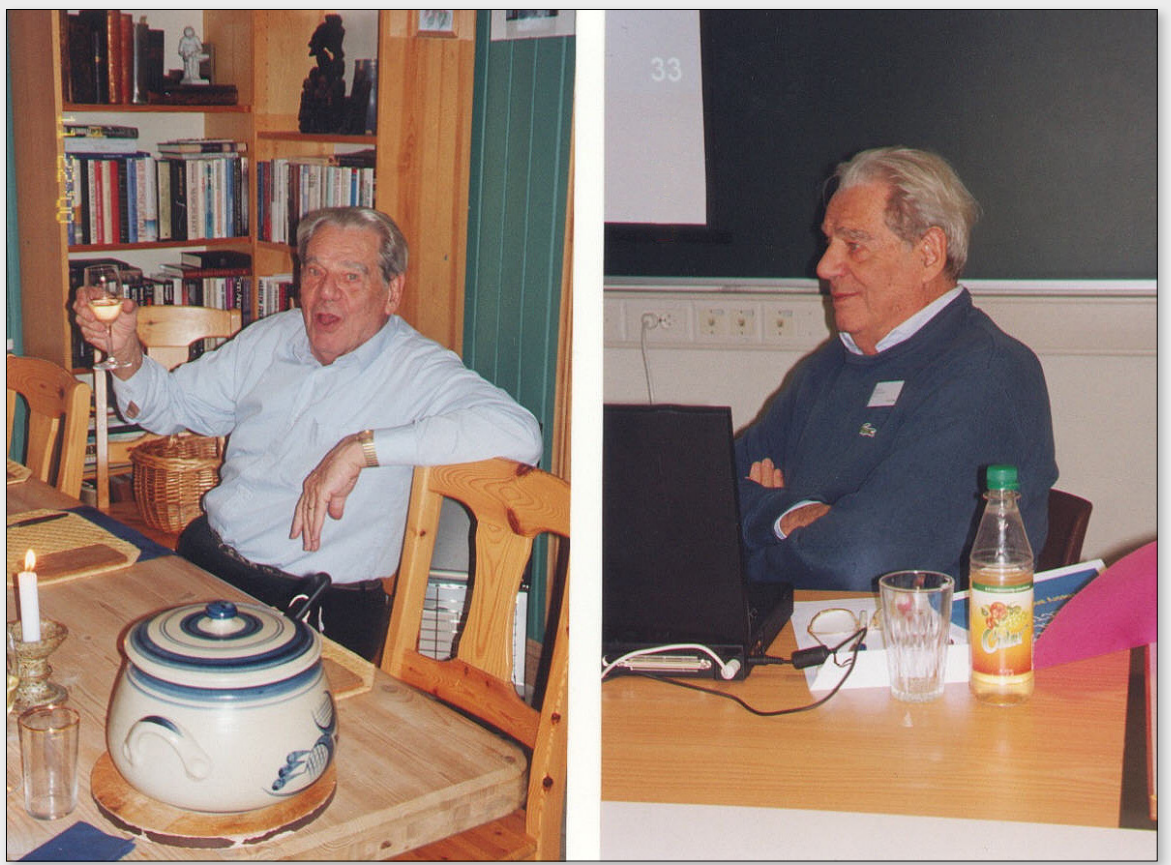

Pierre Gy again in Norway. He lectured with gusto and perseverance (right) and partied with even more... (left).

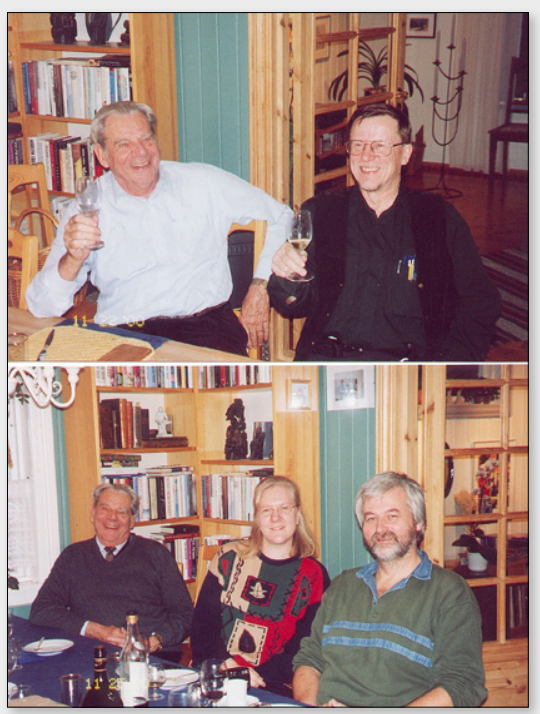

Very few words needed, if any - a thoroughly good time was had by all.
WCSB1 (2003). While the scientific aspects of this inaugural conference and its successive bi-annual followers are now well known and documented within the sampling community and need no space here, ${ }^{2}$ the personal aspects of WCSB1 for Pierre and the sampling community are of interest to our community.

WCSB1 (2003) was, naturally, the first WCSB conference Pierre attended, and he was en plein forme. As were all other participants. Before the conference, professional samplers had worked as individuals for decades: the conference provided the first time they had an opportunity to meet at the same place, at the same time. Much to Pierre's satisfaction, only a few could not, or decided not to, be present. All told, a total of 137 participants attended this inaugural world conference. The conference was held in the conventional format, but with the deliberate aim to honour one man and his monumental scientific oevre. It is no coincidence that the proceedings from WCSB1 were produced as a special issue of an established, peer-reviewed journal Chemometrics and Intelligent Laboratory Systems, ${ }^{3}$ so as to be easily available for all posterity.

In 2003, Pierre agreed to write a summary of the Theory of Sampling (TOS), but only after considerable persuasion. As soon as it got underway, however, the opportunity completely overshadowed all his earlier reservations. In fact, this summary ended up being five full papers, which formed a work of 67 printed pages: three technical summaries of TOS, one complete bibliographic record and a very special "personal history".

"Part IV: 50 years of sampling theory-a personal history" was to become seminal. This is where Pierre Gy tells his own story of the gestation, development and fruition of TOS, which took 25 years, followed by another 25 years of intense and diverse applications. It is a story that is closely intertwined with the twists and turns of his personal life that Pierre reveals as he lifts the veil of privacy a fraction for his otherwise closely guarded private and family life. In a sense, with the passing of time and with Pierre's death in 2015, history would dictate that his "personal history" would become his scientific testament. ${ }^{4}$

WCSB1 saw a confluence of several threads of preceding individual activities and developments, in the form of a broad set of TOS-related topics being presented for the first time in a forum of colleagues and peers. This lead to intense, satisfactory scientific debates, interspaced with personal presentations and inter-personal resolutions of earlier perceived differences and (what turned out to be) misunderstandings. Pierre, Dominique Francois-Bongarcon,

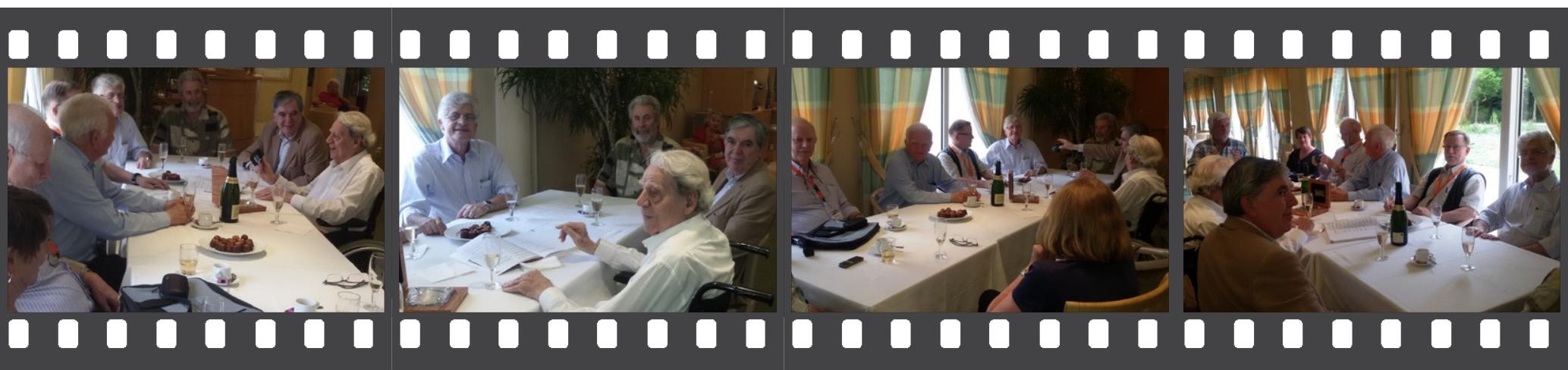


and in particular Francis Pitard gave very personal testimonies from the pre-2003 history of TOS and of the then dispersed sampling community. These were eye-opening insights for all younger participants. WCSB1 was both reconciliatory and visionary, opening new doors for individual interaction and for our community to prosper from.

In the present context it is fitting to convey Pierre's personal reactions to WCSB1. There is perhaps no better documentation than the photograph (originally published in the WCS1 Proceedings) bearing the caption "Pierre Gy with wife Sylvia at the WCSB1 banquet, August 2003" (see page 7 ). It has been said a picture is worth a thousand words: indeed the smiles and the general mood say it all. His reaction to "all this attention" made the work involved in inaugurating a world conference series eminently worthwhile. Below follow a few more, mostly un-published photographs from WCSB1 that I hope succeed to convey Pierre's general pleasure and emotions.

\section{From conferences to Cannes and beyond}

These two conferences, straddling the Millennium, helped to start inducting TOS into the data analytical community (indeed also

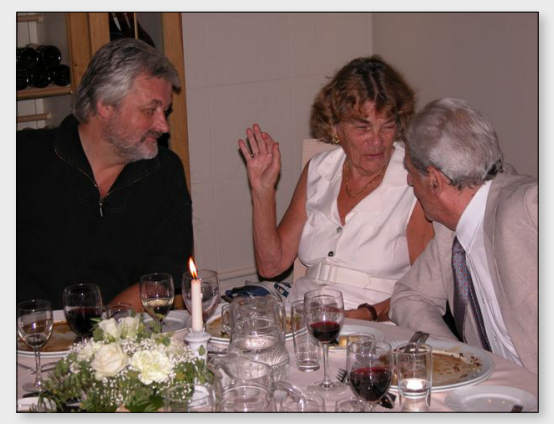

WCSB1 gala dinner. A very good time for Pierre and Sylvia - and the chairman could not be happier. into the powder science and technology community, see reprinted paper by Pierre himself elsewhere in this issue). It must be admitted, however, that progress has not exactly been at dizzying speeds or had the significant impact anticipated-yet: Telling DATA ANALYSTS that their data are contaminated with a whole new class of significant uncertainties, the never-beforeheard-of sampling errors, uncertainties that very likely dominate in magnitude, is understandably a slow process... some things require time and a willingness to take a fresh, objective view, but the start was made! It is obviously much more directly relevant to incorporate the essentials of TOS in powder science and technology.
After these events, activities for the sampling community quickly accelerated as a function of our biennial WCSB conferences-but Pierre was sadly never able to attend again. Despite this, however, contact was not lost. A small group of friends and colleagues (FFP, DFB, KHE, POM) undertook to visit Pierre in his hometown of Cannes every year if possible. This succeeded rather well. These visits became the new order of contact between Pierre and the by now rapidly growing and developing society of samplers, focused on conveying how well TOS was faring and sharing the many success stories that had quickly accumulated. It became customary at these occasions to hand over a copy of the proceedings from the preceding WCSB
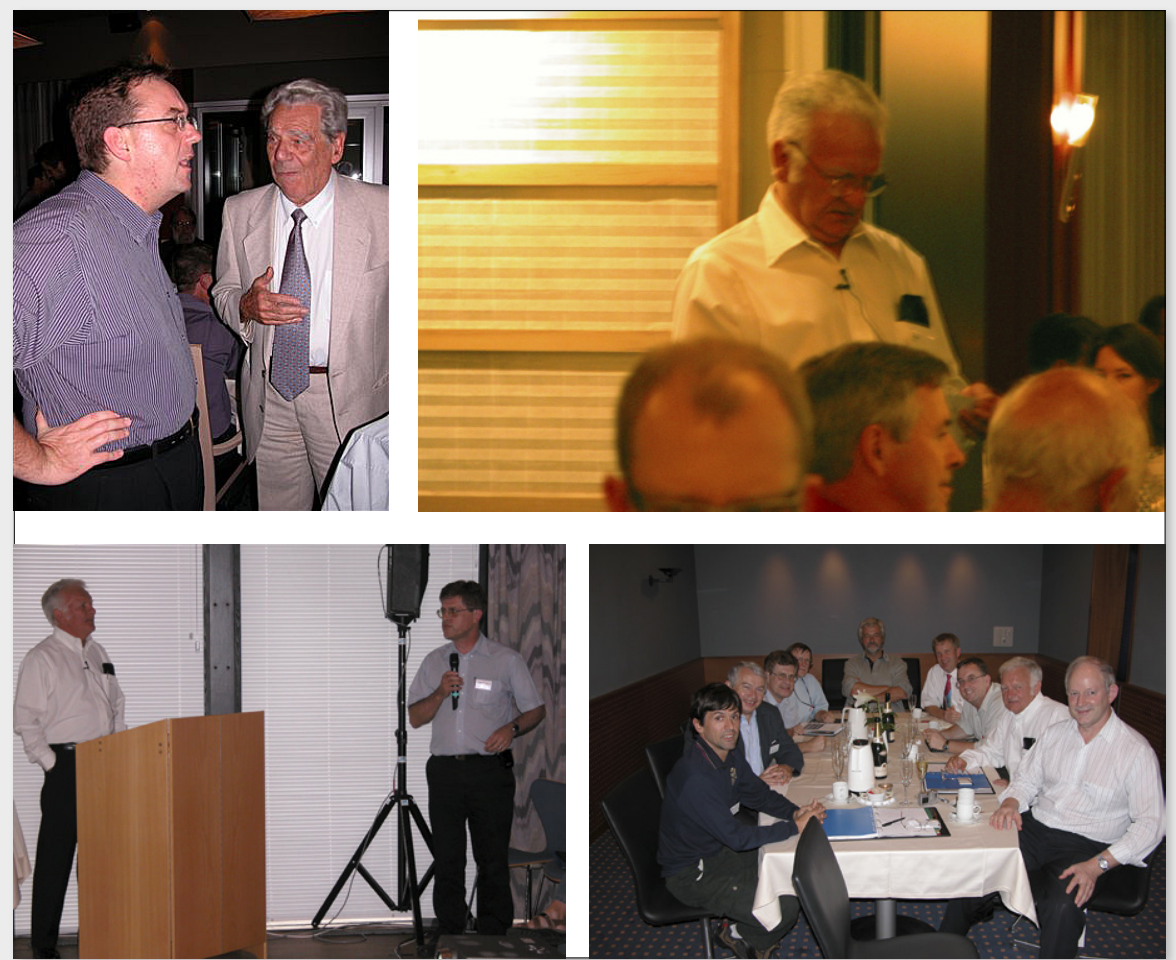

WCSB1 snapshots, never-before-published. Bottom-right: the first ever official "committee" of the sampling community.

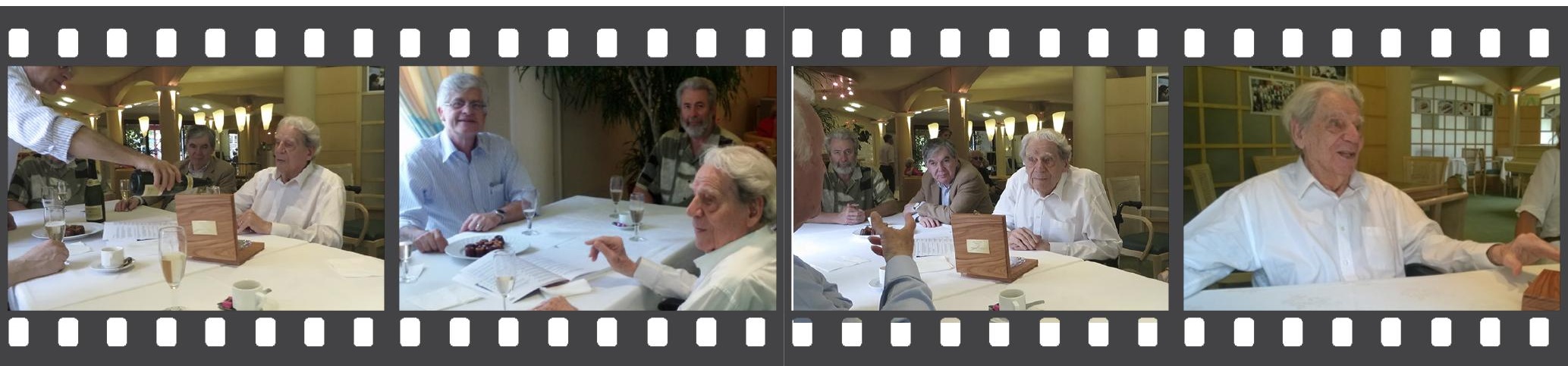


complete with signatures and greetings from a majority of the participants. These communal greetings became a vehicle for communication from the society at large to its respected originator; Pierre truly treasured this missives.

On the lighter side, a wonderful tradition developed at these meetings. At Pierre's insistence, after long walks through his beloved city and waterfront, a lunch at one of the fine seafood restaurant in Cannes was mandatory (always paid for by Pierre, not negotiable).

Nice as these culinary excursions in Cannes were, coffee was always taken afterwards on the balcony of Pierre and Sylvia's spacious apartment at Res. de Luynes, which was also the setting for his customary greeting at the beginning of any visit at which champagne and foi gras were de rigeur. There is much to say about French hospitality and traditions!

In between there also were ad hoc visits when the occasion presented itself, for example one by DFB and KHE in 2005 where Pierre insisted on giving a "guided tour" of his office (barely $10 \mathrm{~m}^{2}$ ) in which a significant part of his scientific production took place. He a.o. proudly showed his classic IBM Electric (the famous red model with its signature exchangeable printing heads) on which two of his major books were produced. His publishers at the time demanded a flawless, print-ready copy of each of $>300$ pages from the author - no editorial or typesetting or editorial help were offered! We also noticed a personal computer (kind of) and when questioned, Pierre explained that he was "dabbling with" transferring his standard lecture presentations into PowerPoint: Pierre at this time was 80 years young. The audacity, drive and technical acumen of an octogenarian scientist impressed me beyond telling. Pierre became a role model in very many ways.
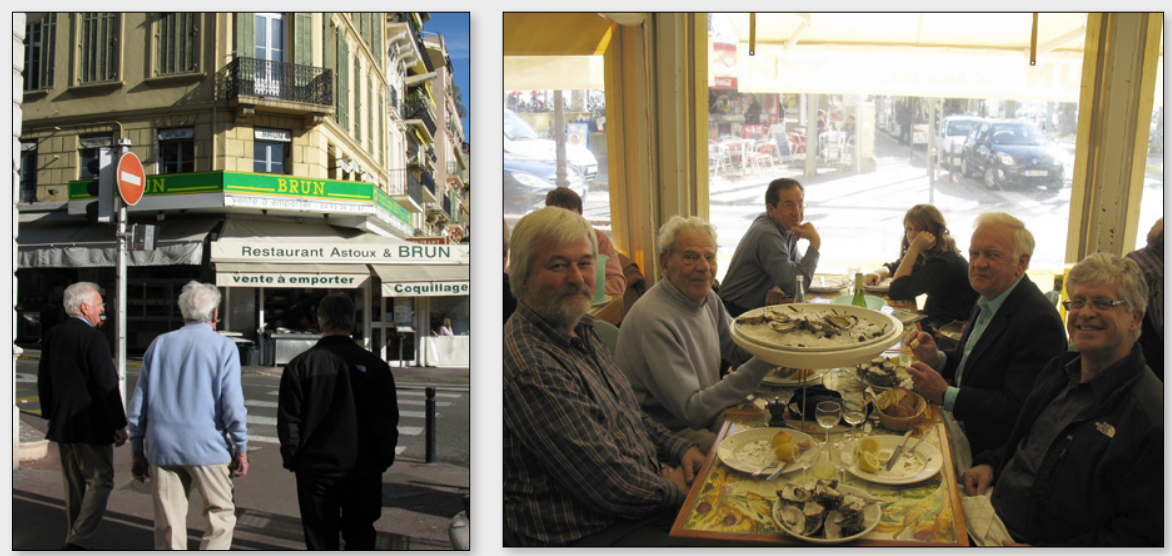

Walks around Cannes very often ended with the imperative oysters \& Loire white wine lunch at "BRUN".
Just about five years into formally teaching TOS at university level, I certainly had not fully developed my curriculum yet, far from, so when requested, my satisfaction reached new heights when Pierre gracefully handed over his entire lecture
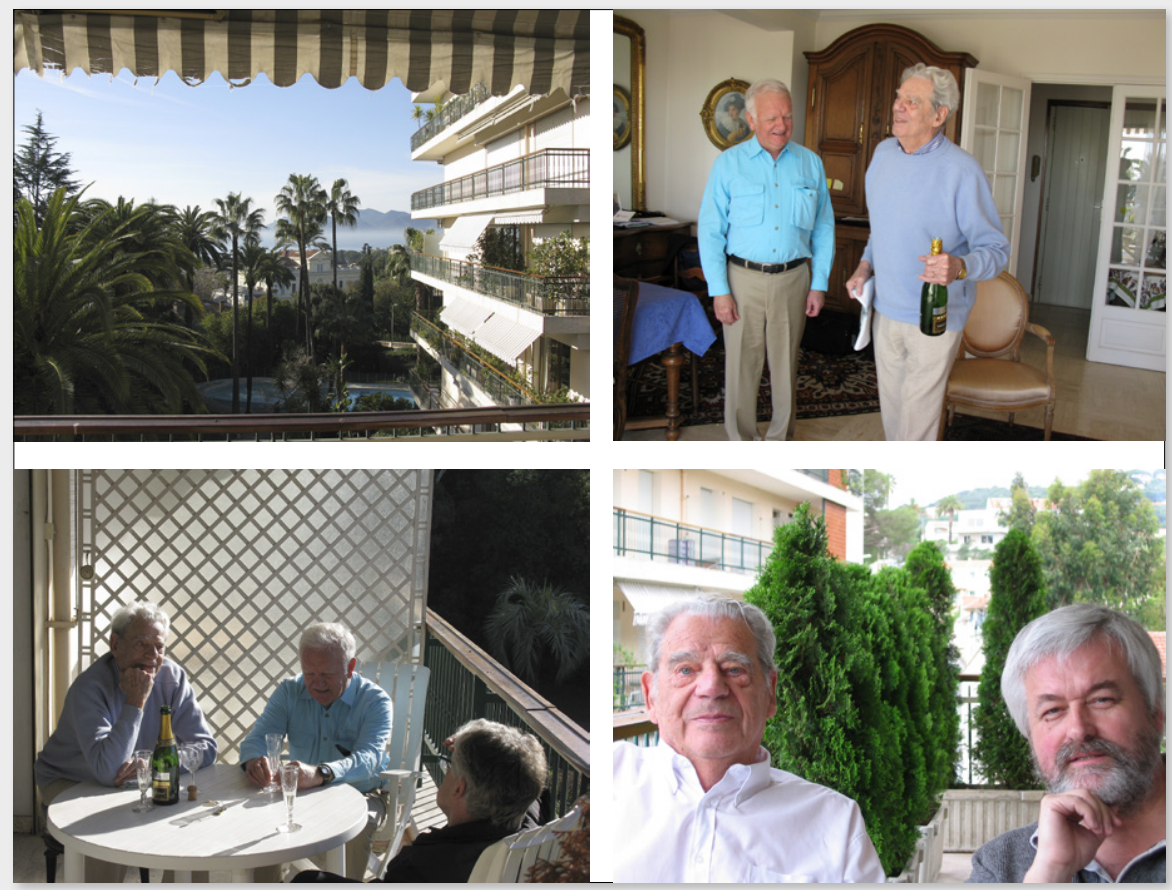

Res. De Luynes, 14 Avenue Jean de Noailles, Cannes - an important place and a terrace to visit.

\section{$\frac{n}{n}$}

000

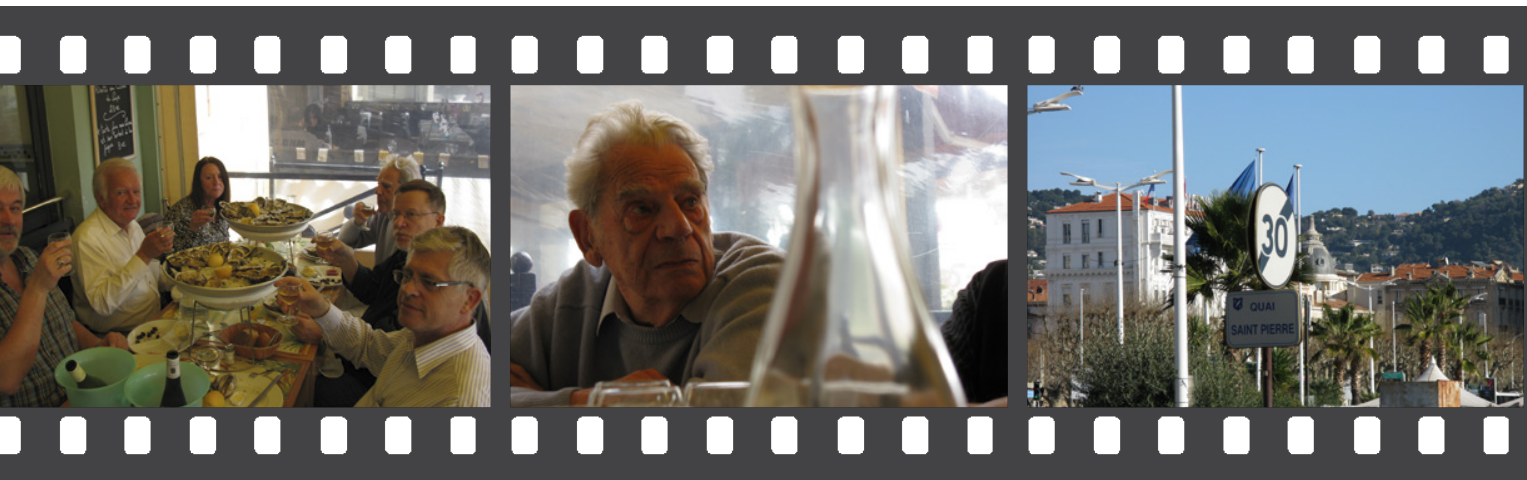



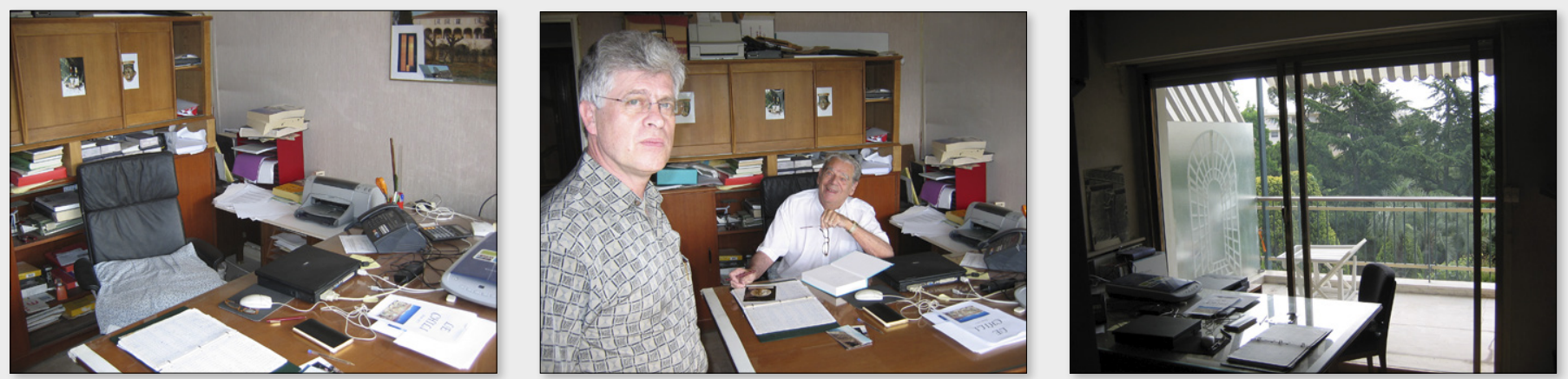

Pierre Gy's office in Cannes - a working place with an inspiring view.

catalogue "for inspiration, to whatever degree this might be possible". I still treasure Pierre Gy's PowerPoint TOS course version as a historic gem from which I drew an enormous inspiration at the time.

These lectures have never been shown to anybody out of respect for a promise to Pierre, but here now a sample can be revealed:

http://www.impublications.com/subs/tosf/ v16/8-Proportional Sampling.ppt

It is of more than passing interest that the theme of this lecture is: "Proportional Sampling", the TOS topic Pierre himself considered the least disseminated, which frustrated him. I have chosen to feature this topic here, especially in connection with the historical feature presented by Phillipe Wavrier: "An automatic linear proportional sampler based on the principles of the Theory of Sampling" (pages 26-28), which we hope will contribute to doing justice to Pierre's wishes.

As always, Pierre was primarily interested in getting the structure of the theory and the mathematical expressions conveyed-he was not much into incorporating many illustrations (he much favoured line drawings): "The equations tell it all".
Well-here opinions actually diverge. I took a decidedly different point of departure from these lectures: "HOW can TOS' curriculum also be told in a different fashion, especially for the mathematically notso-gifted?" This became the hallmark for all my work on the didactics of teaching TOS to a, hopefully, much broader circle of students, clients, companies and various audiences not familiar with TOS.

Our group or individual visits became more and important to us as there was always an acute realisation that sometime in the near(er) future Pierre's situation could change. But this simply increased our determination to continue providing context, information and friendship to Pierre.

Our last meeting with Pierre was at the hospice in Bordeaux where he spent his last years. Despite intense invitations from the WCSB7 committee to attend, or briefly just visit, the conference, he expressed reluctance that he did not wish to do so, with the stated concern: "I would be so embarrassed that I will perhaps not remember all the faces (and names) I should remember". However, the end of the conference, there came a message from the hospice that Pierre would be prepared to see some of us the next day, in the afternoon. The meeting was set up through the tireless intervention of Dominique Francois-Bongarcon. On this occasion it was a wonderful surprise that Pierre's daughter, Caroline, was able to join us. As it took place in the age of "smart technology" two video recordings (mobile phones) are able to document the meeting which can be downloaded from page 46 .

The video recordings attest to Pierre's presence and happiness to meet with close friends and colleagues, many of which go back over much of his entire professional life. Not surprisingly Pierre also here insisted on champagne to accompany the chocolate treats we brought him (not entirely to the satisfaction of his carers, but of course this was a rare and special occasion). The degree to which he appreciated these gourmet delights is evident. The videos also highlight how much he still cherished perusing the signed copy of the WCSB7 Proceedings as well as seeing the $7^{\text {th }}$ Pierre Gy Sampling Gold Medal, which had been awarded to Ralph Holmes at the conference gala dinner the evening before.

\section{An award of a different nature} At the risk of violating the rules of a certain well-known international institution, the following also relate to Pierre Gy's extraordinary scientific life and achievements. For a period of ten years, while in a position as
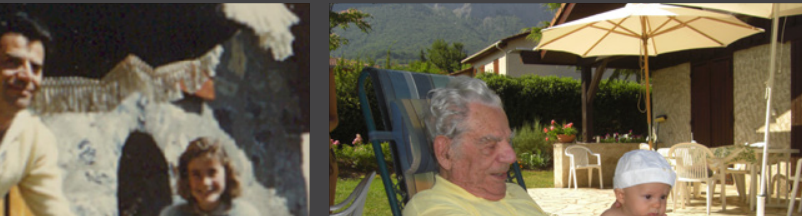
"professor of chemistry" in Scandinavia, I was regularly invited to suggest candidates for the Nobel Prize in Chemistry. One is not often in a situation in which a response to the pertinent committee feels relevant. And for understandable reasons the complete lists of candidates submitted in the office of the Nobel Committee are normally not divulged. However, in the context of our tribute to a scientific giant, it is entirely fitting to disclose that Pierre Gy was indeed suggested, several times, as a candidate for the Nobel Prize in Chemistry.

\section{Pierre Gy, the scientist and the family man}

I was only granted to share a little over 15 years in this world together with Pierre, who died on 5 November 2015. The impact, however, feels like that from a complete professional career. I have never met a scientist of such brilliance (TOS is transcendental),

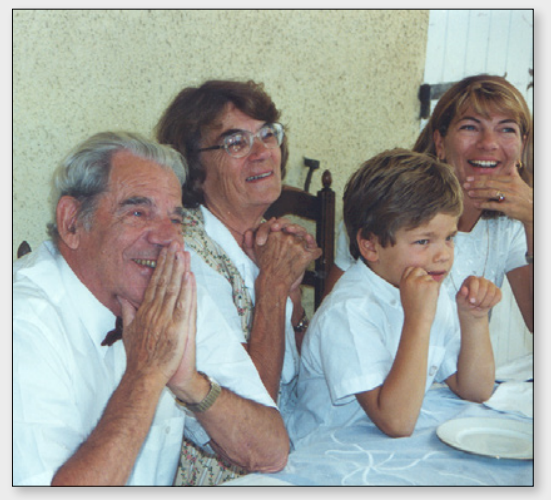

Pierre, Sylvia, grandson Stanislas and daughter Caroline.

character (modesty) and moral standing. The legacy of Pierre Gy, the scientist is first and foremost embodied in his monumental Theory of Sampling, the significance of which is commented in full in this issue, as well as

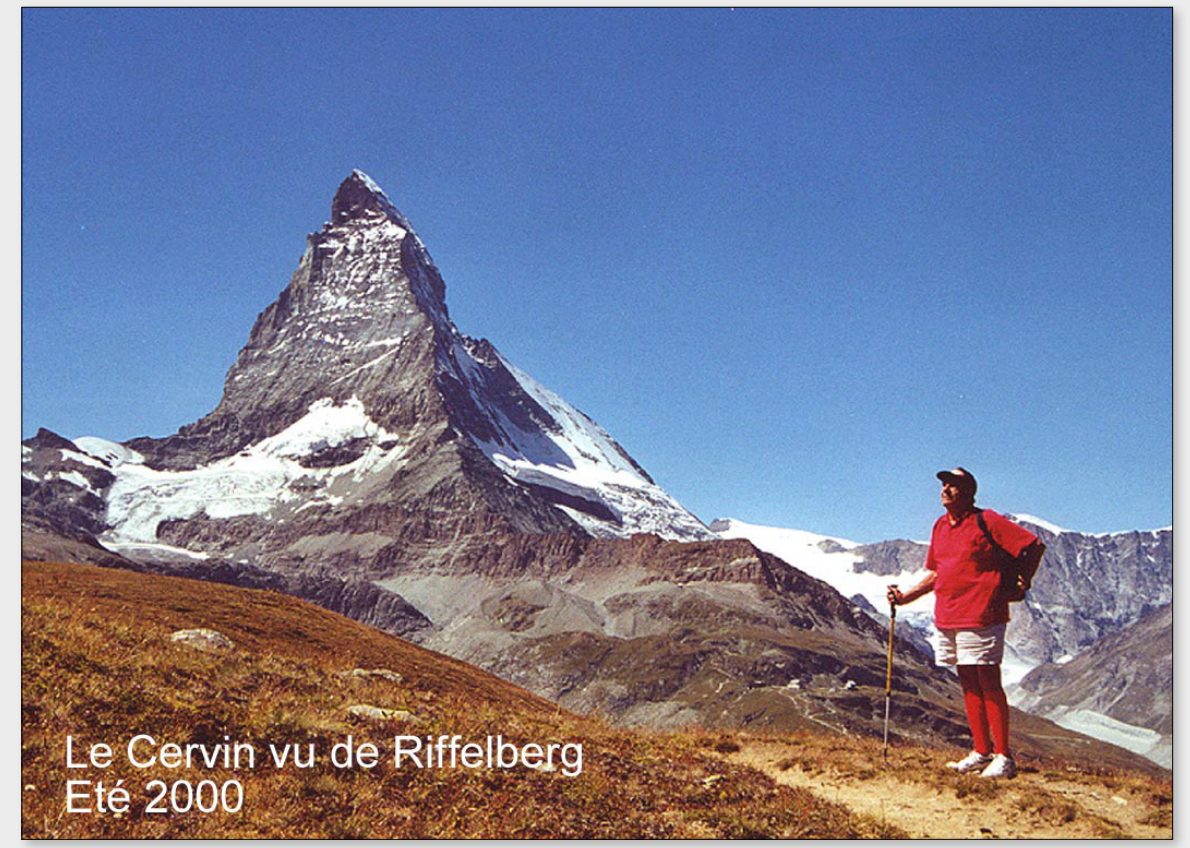

Pierre on one of his walking tours in the Alps.

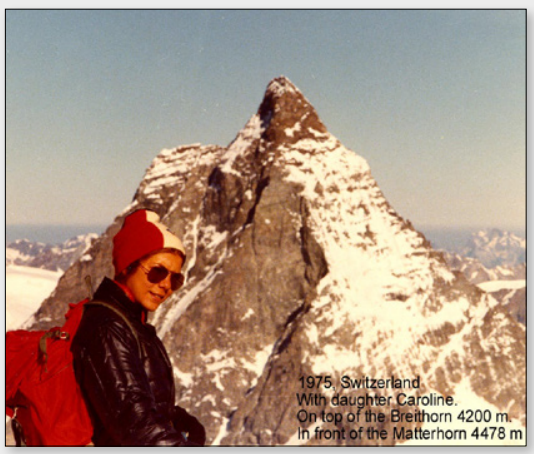

Pierre's daughter, Caroline, in front of the Matterhorn in 1975.

in many other places. For this reason I here focused on a slightly different angle of his life by conveying a view of a few, but seminal interactions between Pierre and the sampling community and to share a few more intimate moments with Pierre Gy, the man.

Pierre Gy is no longer with us. Scientifically, for me this is like I have lost a father. The sorrow is still almost unbearable, I miss him every day.

But we must (also) move forward. We shall cherish his inspirational life, now more than ever. There is a whole world out there that (still) needs to know more about TOS. What greater contribution to his legacy then doubling our efforts in this regard! And in a world characterised by senseless, indeed mindless, competition and ruthless personal ambitions, Pierre's attitude toward life was the direct opposite: collaboration and respect to the fore, endless willingness to help others... a truly monumental life!

I hope the collective efforts and the utmost respect from our entire community to honour Pierre Gy, scientist extraordinaire, will be able to impart but a small solace for his family.

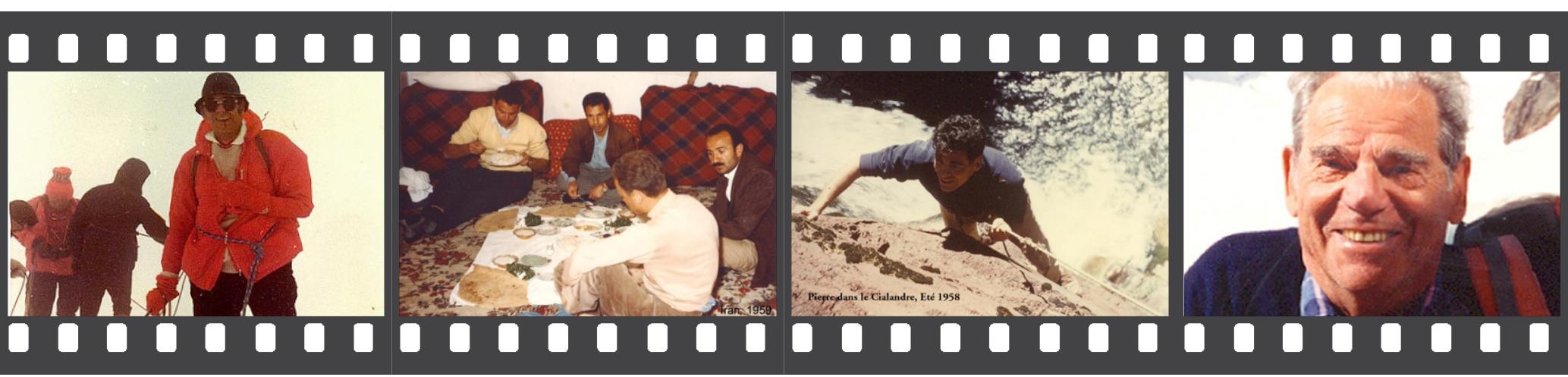




\section{References and notes}

1. There is one person in this world who strongly argues that I should have seen this light "at least 10 years earlier". The reader need not go any further than another of the personal tributes in this special issue to latch on to this claim; which is entirely true of course.

2. K.H. Esbensen (Ed.), "Special Issue: Proceedings of the SSC6, August 1999, HiT/TF, Norway", J. Chemometr. 14(5-6), 381-776 (2000).

3. K.H. Esbensen and P. Minkkinen (Eds), "Special Issue: 50 years of Pierre Gy's Theory of Sampling. Proceedings: First World Conference on Sampling and Blending (WCSB1).
Tutorials on Sampling: Theory and Practise", Chemometr. Intell. Lab. Syst. 74(1), 1-236 (2004).

4. Reprints of the full proceedings issue (236 pages) are available at the Publisher's on-line print-on-demand facility. Elsevier B.V. is owed much gratitude for their kind permission to bring six items from these proceedings into this special issue "two full-length re-reprints and four open access papers in downloadable electronic format".

5. The Editor and the Publisher of the present issue are delighted by the very kind permission given by Elsevier B.V. to reprint this sinequa-non historical item here.

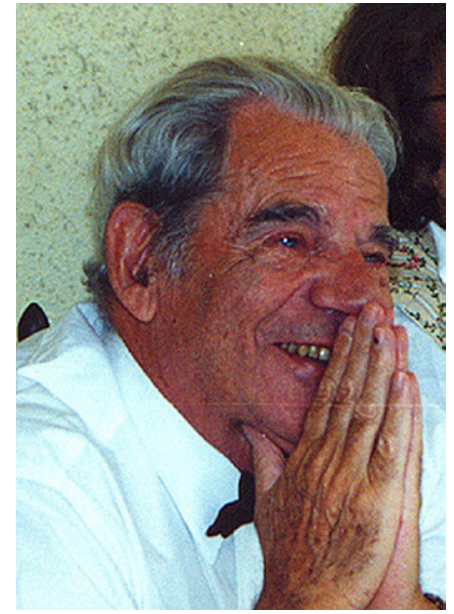

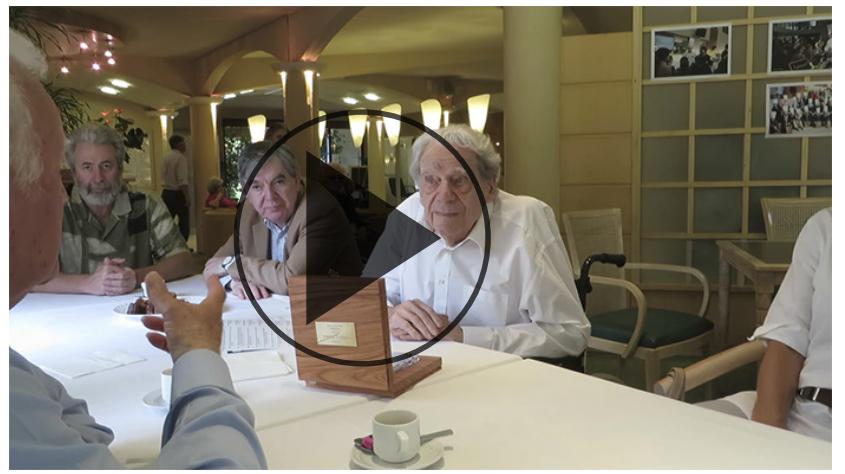

http://tosf.s3.amazonaws.com/Gy-1.mp4

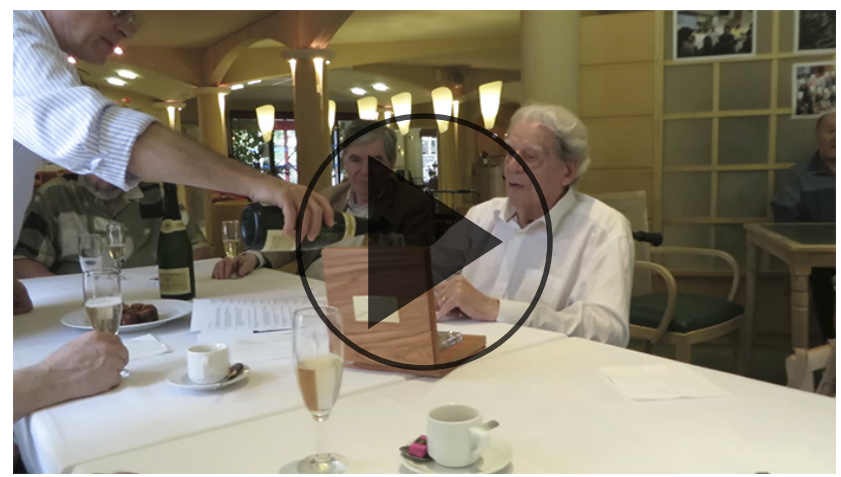

http://tosf.s3.amazonaws.com/Gy-2.mp4

\section{SPECTROSCOPY europe}

Informing European spectroscopists for 40 years

Spectroscopy Europe is a free magazine for all interested in spectroscopy, available in print (within Europe), on the web, as apps for both Apple and Android devices and in a Digital Edition.

With its Sampling Column edited by Kim Esbensen and Claas Wagner introducing readers to the importance of representative sampling, it will be of particular interest to readers of TOS forum.

Download the app from the App Store or Google Play-just search for "spectroscopy europe". All the 2015 to 2013 back issues are already available to you when you install the App. Accept notifications from us, and you will know as soon as the latest issue is published.

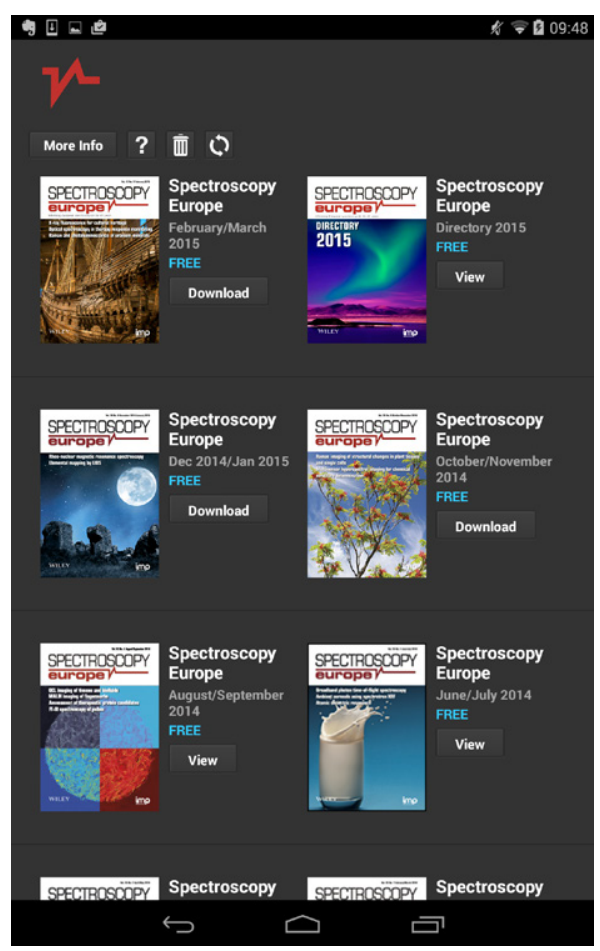

